\title{
Consumers' experiences of appropriate sales interaction - a speech code theory perspective
}

\author{
Jonna Koponen, University of Eastern Finland, Department of Business* \\ Saara Julkunen, University of Eastern Finland, Department of Business \\ *Corresponding author: jonnapauliina.koponen@uef.fi
}

\begin{abstract}
Little is known about what kind of salesperson-consumer interaction is valued in different cultures. We explore the influence of national speech culture in sales-related communication in business-to-consumer (B2C) environments. We apply speech codes theory to identify the B2C context-specific speech codes attached to the sales-related communication described in consumers' narratives. The results inform three discourses among sales-related communication: consumer orientation, professionalism and independency. The results suggest that independency, fact-oriented talk, and consumer-oriented communication are central speech codes related to the B2C sales context in Finland. Furthermore, the results describe a cultural norm for appropriate sales-related communication.
\end{abstract}

\section{Keywords}

Salesperson-consumer interaction, national speech culture, B2C environments, speech codes, discources, appropriate sales-related communication

\section{Introduction}

Salesperson-consumer interaction lies at the heart of the sales process. The literature on sales gives general guidelines for good communication within the sales process (Moncrief \& Marchall, 2005; Weitz, Barton, Haris, \& Sujan, 1986) that are often related to a business to business (B2B) sales context. Focusing on consumers, there is a huge number of studies on consumption (e.g., Warde, 2005, p. 131; Miller, 1995) alongside studies of consumers' decision-making (e.g., Blackwell, Miniard, \& Engel, 2003) and consumers' behavior (Calder \& Tybout, 1987). The consumer research proposes that consumers have "persuasion knowledge" (e.g., beliefs related to salespersons' strategies and aims) that they may use as part of their decision-making in purchasing situations (Friestad \& Wright, 1994). The knowledge involves how consumers negotiate with marketing professionals and how their cognitive and physical actions before, during, and after purchasing influence these situations (Kirmani \& Campbell, 2004).

Although interpersonal communication between salespersons and consumers has been recognized as an important element of the sales process in the sales literature (Moncrief \& Marchall, 2005; Mason \& Leek, 2012), salesperson-consumer interaction within the personal selling process has remained rather unexplored from the consumer's perspective (Blackwell et al., 2003; Evans, McFarland, Dietz, \& Jaramillo, 2012). The current sales research lacks understanding of consumers' experiences of salesperson-consumer interaction. Furthermore, more understanding is needed about how these experiences are produced for consumers with sellers in different cultural environments. We extend the extant sales research, suggesting that appropriate or inappropriate salesperson-consumer interaction can be understood through the speech culture in which it is embedded. We also claim that the cultural environment has an impact on consumers' perceptions of effective or ineffective salesperson-consumer interaction and thereby it has an 
impact on consumers' decision-making. To achieve a competitive advantage, managers are therefore required to guide their sellers to build sales interactions that involve a profound understanding of speech culture and the speech codes embedded in the salesperson-consumer communication context.

In this study, we explore the speech codes embedded in salesperson-consumer interaction in Finnish speech culture. We approach culture as a code of values, meanings, and behavioral norms that constrain but do not dictate the communication of the members of a culture (Philipsen, 1997). Speech codes are "historically situated and socially constructed systems of words, meanings, premises, and rules that people use to talk about their own and others' communicative conduct" (Philipsen, 2008, p. 273). We apply speech codes theory (Philipsen, 1992, 1997, 2008) - using it as a theoretical lens through which to analyze the meanings, values, and norms attached to the salesperson-consumer interaction described in the narratives of Finnish consumers - and we analyze the discourses embedded in these narratives. Through the analysis of discourse, we target three research questions:

1) Which discourses are embedded in the narratives of salesperson-consumer interaction?

2) What kind of speech codes build discourses in the narratives of salesperson-consumer interaction?

3) How are appropriate and inappropriate salesperson-consumer interaction defined through speech codes in the discourses?

\section{Research into salesperson- consumer interaction}

The business literature focuses on marketing interactions through communication, psychology, management, and marketing studies that are often based on strategies used by persuasion agents (e.g., sales professionals) to influence targets (Kirmani \&
Campbell, 2004). Lots of attention is also paid to "viewing the influence process from the perspective of the target" as Kirmani and Campbell (2004, p. 673) state in their study.

Studies of salesperson-consumer interaction have investigated the salesperson's communication skills - for example, their listening skills and impression management skills (Malshe, 2004) - the salesperson's use of influencing tactics (Evans et al., 2012), and the consumer's expectations of the salesperson (Williams \& Semineiro, 1985; Blackwell et al., 2003). The sales literature even shows them as key elements of successful sales (Abratt \& Kelly, 2002; Hung \& Lin, 2013), and they may create new value (Guenzi \& Storbac$\mathrm{ka}, 2015)$ in buyer-seller relationships in B2B contexts. Some specific theoretical approaches have been used to explore salesperson-consumer (B2C) interaction, for example, by proposing a contingency framework (Weitz, 1981) or facework theory (Planken, 2005); however, speech codes theory has not been applied to the study of salesperson-consumer interaction. That is why we lack understanding of how salesperson-consumer interaction is linked to the cultural environments in which it occurs. It is important to investigate B2C communication in order to understand what kind of salesperson-consumer interaction is valued in different cultures and especially in the B2C sales context, since it gives managers new knowledge on how to guide their sellers to successfully communicate with their consumers.

\section{Speech codes theory and Finnish speech culture}

Speech codes theory aims to identify, describe, interpret, and explain observed communicative conduct in particular places and times (Philipsen, Coutu, \& Covarrubias, 2005). Speech codes are constructs that observer-analysts formulate explicitly in order to interpret and explain communicative conduct within a particular speech community (Philipsen et al., 2005). The theory posits a way to discover 
and describe traces of culture in communicative conduct, and it has its roots in a large body of fieldwork about cultural ways of speaking (Philipsen \& Carbaugh, 1986). The speech codes framework conceptualizes culture as a code system that lays out meanings and ideals (Miller, 2002). Culture is seen as a socially constructed and historically transmitted pattern of symbols, meanings, premises, and rules (Philipsen, 1992). Thereby, culture functions to guide and constrain behavior, to coordinate behavior in a recognizable way, and to integrate and bind cultural members (Miller, 2002).

Philipsen and his colleagues formulated six theoretical statements that form the core of speech codes theory (Philipsen, 1992, 1995, 2008; Philipsen et al., 2005). They firstly state that wherever there is a distinctive culture, there is a distinctive speech code to be found. Secondly, they state that every individual will encounter multiple speech codes during a lifetime and that more than one speech code is used in one society. Thirdly, in every speech code, the words, meanings, premises, and rules pertaining to communicative conduct are systematically linked with the nature of people and of social relationships. Fourthly, they state that the significance of a particular communicative act is contingent upon the speech codes used to constitute the meanings of communicative acts. Fifthly, their proposition shows that the words, rules, and premises of a speech code are inextricably woven into the communicative conduct. Thus, this proposition causes us to look at and listen to communicative conduct and search for the usage of a cultural code or codes. Lastly, the theory states that people use speech codes not only to interpret communicative conduct but also to evaluate it as being good or bad, to explain it, and thereby to justify it. Speech codes (such as the code of honor) are constructs that are formulated by observer-analysts who are aiming to explain and interpret communicative conduct in a given speech community (Philipsen, 1992; Philipsen et al., 2005; Poutiainen \& Gerlander, 2009).
In this study, we investigate the speech codes embedded in Finnish speech culture in salesperson-consumer interaction. Pecoraro and Uusitalo (2014, p. 47) state that Finland is a small country (5.8 million inhabitants) located in the interface between East and West. Even though Finland closely belongs to the Scandinavian area, it is often defined to be linguistically unique (see Wilkins \& Isotalus, 2009). We have chosen Finland as an example country since it is a very homogenous country in Europe (Wilkins \& Isotalus, 2009), Finns have unique genetic ancestry (Lek et al., 2016), Finnish speech culture has identifiable characteristics (Virtanen, 2015; Wilkins \& Isotalus, 2009), and previous research has suggested that there might be speech codes embedded in Finnish speech culture (Wilkins 2005, 2009; Poutiainen \& Gerlander, 2009).

At the national culture level, Virtanen (2015) states that the Finnish culture has not been extensively researched on Hofstede's (1980) value dimensions or Hall's (1977) low-context dimensions versus high-context dimensions, which are commonly used to explore cultural values in cross-cultural communication studies. However, Finnish speech culture is known for valuing silence (Virtanen, 2015; Wilkins \& Isotalus, 2009). Finns have been shown to have communication reticence in some contexts (Sallinen-Kuparinen, 1986) and Finns often feel themselves less talkative or lacking small-talk skills compared to other cultures (Virtanen, 2015; Wilkins \& Isotalus, 2009). After all, Finns are also proud of their speech culture (Wilkins \& Isotalus, 2009), of how they put careful weight on words, and of how they are very thoughtful in interaction situations (Virtanen, 2015). Moreover, Finnish speech culture has been described to be listener-centered in a sense that the role of the speaker is not emphasized and participants of the interaction recognize the importance of the listener's role (Virtanen, 2015).

Finnish speech culture has been explored in different contexts with the focus on foreign language acquisition (Berry, Carbaugh, \& Nurmikari-Berry, 2004), political communication (Isotalus, 2009), 
communication in public and civic settings (Wilkins, 2005), educational communication (Poutiainen \& Gerlander, 2009; Wilkins, 2009), courtroom communication (Välikoski, 2009), supportive communication (Virtanen, 2015), and business communication (Vaahterikko-Mejía, 2009). Carbaugh $(1995,2009)$ explored cultural terms for talk, and especially silence and quietude, as a Finnish natural way of being. However, salesperson-consumer interaction as a particular communication context within Finnish speech culture has not been explored. In this study, our aim is not to generalize our results to a larger Finnish public and the varied contexts for speaking within this speech culture but to pay closer attention to the Finnish consumers' language and their experiences of salesperson-consumer interaction.

Few studies have suggested that there might be speech codes in Finnish speech culture. Wilkins (2009) explored a speech event identified as asiasta puhuminen (hereafter matter-of-fact) in scenes of adult education in Finland. His conclusions show that the matter-of-fact event evokes an impersonal and infocentric structure for public participation in adult education settings in Finland when compared with more egocentric and sociocentric motivations for speaking in other communities. Matter-of-fact talk highlights the underlying beliefs and values of being, relating, and communicating in Finnish educational settings (Wilkins, 2009; Poutiainen \& Gerlander, 2009). Furthermore, a study concerning Finnish advisor-advisee relationships found four relational dialectics, one of them being fact-orientation in personal relating (Poutiainen \& Gerlander, 2009). When Poutiainen and Gerlander approached dialectics as cultural phenomena, they found that in the talk about advising, the values related to independency and fact-orientation were most strongly expressed. Independency was particularly found to be a demand for advisees: they were valued for being self-directive and getting along by themselves (Poutiainen \& Gerlander, 2009, p. 109). Therefore, they state that independency and matter-of-fact events could be approached as cultural codes, particularly in Finnish educational settings. Previous studies have not, however, concentrated on salesperson-consumer interaction in the $\mathrm{B} 2 \mathrm{C}$ selling context. In this study, we therefore explore the speech codes in discourses embedded in salesperson-consumer interaction in the B2C selling context, and we argue that sales managers and sellers need more understanding of the influence of speech codes on sales communication between consumers and sellers.

\section{Method}

\subsection{Study design and data gathering}

The study combines participant observation research with narrative data collection and discursive methods of analysis (Makkonen, Aarikka-Stenroos, \& Olkkonen, 2012; Van Laer et al., 2014). The data for the study consists of 50 narratives (600 pages / 252000 words) reported by 50 Finnish university students (their age ranging from 21 to 59) who worked as research assistants. Data were collected during four years (2011-2014). The students studied different majors in the University of Eastern Finland (business, pharmacy, environmental sciences, nursing and social sciences) and their nationality was Finnish. They all participated in a Sales Work course, which was part of their minor studies. Due to their different ages, genders, study backgrounds, and work experience, the students were accepted as representing different types of consumers. We advised them to behave in a way that was typical for them as a consumer. They were asked to focus on their personal experiences. They were in particular expected to observe salesperson-consumer interaction from the consumers' perspective in stores or hypermarkets selling typical consumer goods, such as domestic appliances, sports accessories, and clothing. They were also asked to focus on the phases of a sales process (Moncrief \& Marshall, 2005) during the sales situations. After observing sales situations, they were advised to write down their real experiences and the feelings they had during the salesperson-consumer interaction. 
All the observed sellers were Finnish who were working in the retail stores that were members of different franchising chains in Finland. The salesperson's age ranged from 20 to 55 years old ( $40 \%$ of the sellers were male and $60 \%$ were female). The sellers' nationality, age, and gender were estimated by the research assistants. Since the salespeople were working at the stores or hypermarkets belonging to different franchising chains, they all had at least the basic sales training offered by the franchising chain and guidelines provided by a local retailer.

In the narratives, the consumers describe the sales processes they had experienced and observed, focusing on salesperson-consumer interaction during the sales process. In addition, they describe their purchasing decision and willingness to continue interaction with the seller in the future. They also describe their willingness to return to the store their narratives are set in. The data collection followed the principles of speech codes theory because we concentrated on observed participatory communication (Philipsen et al., 2005). The method is called "hunt-and-peck ethnography" (Whyte, 1984), which focuses on understanding consumption phenomena across a variety of sites.

In this study, the logic of producing narratives based on participant observation of salesperson-consumer interaction lies in several issues. First, narratives provide a meaning structure for organizing and understanding human life (Polkinghorne, 1988). Second, narratives are based on individual experiences and draw linguistic resources from a shared cultural knowledge base (Rappaport, 2000). Third, narratives easily emerge from the interaction between the storyteller and the environment (Bruner, 1986). In narratives, people reflect their lives, experiences, and concerns combined with real events in their environment (Polkinghorne, 1995; Gilliam \& Flaherty, 2015). The method can be regarded as being very useful in the investigation of speech codes and communication practices in sales.

\subsection{Analysis}

The importance of cultural discourse is often used as a prime methodological approach to explore cultural models, including environmental influences on individuals (Thompson \& Haytko, 1997). Moreover, it is often highlighted among consumer behavior studies (e.g., Thompson, 2004; Thompson \& Haytko, 1997; Thompson \& Hirchman, 1995). In this study, our aim is to identify B2C context-specific speech codes that produce the discourses of the different narratives (Makkonen et al., 2012) when describing salesperson-consumer interaction.

The research assistants gathered all data and wrote the narratives based on their experiences as consumers. The gathered narratives were transcribed, encoded, and structured by two researchers by using qualitative content analysis, which is also referred to as discourse analysis (Focault, 1982). Multifaceted narratives are connected to the earlier literature to offer the discourses as constitutive constructions of the social world - the world cannot be known separately from discourses (Phillips \& Hardy, 2002). The discourses can be therefore seen as meaning frames (Edwards, 1997; Hall, 1997) that can describe a common perspective for a chosen phenomenon. Specifically, discourses produce cultural meanings attached to sales.

We first analyzed the contents of the narratives inductively (Eriksson \& Kovalainen, 2008, p. 219) and identified thematic discursive elements of the narratives. A theme was defined as a consistent trend emerging from the data (Eriksson \& Kovalainen, 2008; Makkonen et al., 2012). Thereafter, we compared the themes that we identified from the narratives in order to categorize them. Through the comparison, we identified three types of narratives that describe salesperson-consumer interaction in distinctively different ways. The first category of narratives (five out of 50) outlines a situation in which the salesperson participates in interaction with the consumer (hereafter "narratives of the active seller"). The second category of narratives (13 out of 50) describes a situation in which the salesperson cooperates with 
the consumer (hereafter "narratives of the cooperative seller"). The narratives in the third category (32 out of 50) describe a situation in which the salesperson withdraws from the interaction with the consumer (hereafter "narratives of the withdrawing seller").

The salespersons in the narratives of the active seller actively made contact with the consumer both verbally and nonverbally. They were interested in consumers' needs and wanted to help the consumers in the purchasing process. The salespersons used various types of questions, appropriate sales techniques, and convincing arguments. The salespersons offered alternatives and guided consumers through the sales process. The salespersons gave friendly, professional, effective, and pleasant impression of themselves. Sometimes the salespersons were, however, overly active, too enthusiastic, or even visibly nervous, and sometimes the salespersons also put too much pressure on the sales outcome. Jobber and Lancaster (2009, p. 17) state that this description emphasizes the seller's willingness to close the sale and his or her emphasis on the product, not necessarily paying so much attention to the customer's needs.

The salespersons in the narratives of the cooperative seller collaborated with consumers. In these narratives the sellers were instantly ready to serve the consumer. The salespersons were flexible to alter their sales strategy and they cared about the consumers during the whole sales process. They wanted to develop a better understanding of the consumers' needs and work together with their consumers to generate the best solution by solving the consumers' problems. The salespersons gave both negative and positive arguments regarding the products, compared alternative products, gave advice, asked questions, gave professional answers, and provided more information about the products. The consumers' described the sellers as friendly, smiling, open, relaxed, calm, and positive. The purchasing decision was reached through cooperation. This description refers to sellers who work on the basis of their consumers' needs.
They firstly aim at a customer-oriented sales process and then aim to close the sale (as defined by Jobber and Lancaster, 2009, p. 17).

The salespersons in the narratives of the withdrawing seller did not actively make any contact with consumers nor did they make any other attempt to identify their consumers' problems or needs. In this category of narratives, the salesperson was considered unprofessional in the sense that no particular sales techniques were used by the seller. They may have used technical jargon or humor in a way that was not considered appropriate by the consumer. Overall, these salespersons gave an unfriendly, rude, inexpressive, and/or nervous impression of themselves. Finally, the consumers were responsible for selecting and comparing the products by themselves, as well as purchasing the products. Behaving in completely the opposite way to how sales research defines skillful salespersons (Saxe \& Weitz, 1982; Sujan, Weitz, \& Sujan, 1988), the "withdrawing" sellers seemed to lack understanding of their customers' needs; they did not have professional knowledge of their products or any motivation to interact with their customers. The narrative types of different sellers are described on a data basis in the following Figure 1.

Figure 1: Three types of narrative

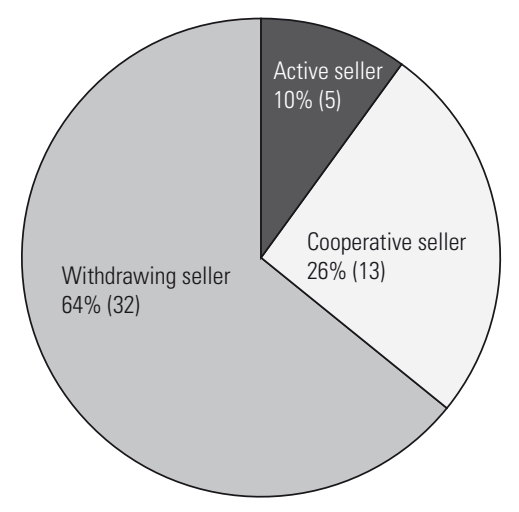

Based on the categorization of the narratives above, we chose one type narrative 
from each category for a fine-grained discursive analysis in order to detect more specifically how Finnish speech culture informs salesperson-consumer interaction based on consumers' experiences. The chosen quotations from the narratives were translated from Finnish to English. In the analysis, the discourses were constructed from the narratives and they were drawn from the characteristics of Finnish speech culture and the speech codes (fact-oriented talk and independence) that prior research suggests to be typical in Finland (see Poutiainen \& Gerlander, 2009; Wilkins, 2005, 2009). In addition, we were searching for other speech codes that could occur in the context of salesperson-consumer interaction. Moreover, the discourses were built by using prior knowledge on appropriate and inappropriate salesperson-consumer interaction, identified by the earlier sales literature and customers' experiences in the narratives. Decormier and Jobber (1993) state that appropriate sales interaction includes salespersons' ability to meet their consumers on a personal level, modify their behavior, and change their sales strategies when needed. In appropriate sales interaction, salespersons probe consumers' purchasing motivation, understand their needs and different sales situations, and help their consumers' in decision-making processes. The opposite, inappropriate salesperson-consumer interaction, lacks some or many of the characteristics of appropriate sales interaction (as described above).

\section{Results}

In the type narratives, Finnish speech culture informs the salesperson-consumer interaction through three discourses: service-orientation, professionalism, and independence. All narrative types draw on these discourses, but in different ways. Each discourse was produced through a speech code that was typical for it: The discourse of service-orientation was built through the speech code of consumer-orientation, the discourse of professionalism was produced through the speech code of fact-orientation, and the discourse of independence was built through the speech code of independency. Both appropriate (Decormier \& Jobber, 1993) and inappropriate sales interaction were found in all discourses and they were related to the

Table 1: $\quad$ Results showing the discourses and speech codes emerging in three different narrative types

\begin{tabular}{|c|c|c|c|}
\hline \multirow{2}{*}{$\begin{array}{l}\text { Discourses and } \\
\text { speech codes }\end{array}$} & \multicolumn{3}{|c|}{ Narrative type } \\
\hline & Active seller & Cooperative seller & Withdrawing seller \\
\hline $\begin{array}{l}\text { - The discourse of ser- } \\
\text { vice-orientation } \\
\text { - The speech code consum- } \\
\text { er-orientation is embedded } \\
\text { in the discourse }\end{array}$ & $\begin{array}{l}\text { - An appropriate, active } \\
\text { communication style } \\
\text { - An inappropriate, too } \\
\text { active communication } \\
\text { style (pushing too hard to } \\
\text { close the sale) }\end{array}$ & $\begin{array}{l}\text { - Appropriate sensitive } \\
\text { communication style and } \\
\text { attentive listening }\end{array}$ & $\begin{array}{l}\text { - Inappropriate withdrawal } \\
\text { from consumer interaction } \\
\text { (not reacting at all, not } \\
\text { showing any interest in } \\
\text { the consumer) }\end{array}$ \\
\hline $\begin{array}{l}\text { - The discourse of profes- } \\
\text { sionalism } \\
\text { - The speech code fact-ori- } \\
\text { entation is embedded in } \\
\text { the discourse }\end{array}$ & $\begin{array}{l}\text { - Appropriate profes- } \\
\text { sionalism (good sales } \\
\text { presentation focusing on } \\
\text { consumers' needs, relaxed } \\
\text { and open interaction with } \\
\text { a consumer, focusing on } \\
\text { facts, giving professional } \\
\text { answers) }\end{array}$ & $\begin{array}{l}\text { - Appropriate professional- } \\
\text { ism (good communication } \\
\text { skills such as asking } \\
\text { questions and listening, } \\
\text { knowing the product, using } \\
\text { sales techniques, solving } \\
\text { the consumer's problems) }\end{array}$ & $\begin{array}{l}\text { - Inappropriate professional- } \\
\text { ism (reluctance to provide } \\
\text { a service, not using any } \\
\text { sales techniques, not } \\
\text { trying to sell anything) }\end{array}$ \\
\hline $\begin{array}{l}\text { - The discourse of indepen- } \\
\text { dence } \\
\text { - The speech code indepen- } \\
\text { dency is embedded in the } \\
\text { discourse }\end{array}$ & $\begin{array}{l}\text { - Appropriate independence } \\
\text { (positive freedom of choice } \\
\text { in the purchasing decision, } \\
\text { being available when } \\
\text { needed) }\end{array}$ & $\begin{array}{r}\text { - Appropriate independence } \\
\text { (positive freedom of choice } \\
\text { in the purchasing decision) }\end{array}$ & $\begin{array}{l}\text { - Inappropriate indepen- } \\
\text { dence (too much freedom } \\
\text { of choice in the purchasing } \\
\text { decision, not being } \\
\text { available when needed) }\end{array}$ \\
\hline
\end{tabular}


types of the different narratives. In Table 1, the results are presented, showing the discourses and speech codes emerging in the narratives of the three different seller types.

\subsection{The discourse of service-orientation} In the sales research, customer-orientation is mostly discussed instead of consumer-orientation, referring to both B2B and $\mathrm{B} 2 \mathrm{C}$ sales. Customer orientation is linked to skillful salespersons (Saxe \& Weitz, 1982) who have an understanding of different sales situations and different types of customers (Sujan et al., 1988). Skillful salespersons have the capability of perceiving that their long-term rewards are positively combined with their understanding of their customers' well-being. The perspective is inseparably combined with the firms' strategic perspective that is most often presented from the very initial sales research (Saxe \& Weitz, 1982; Sujan et al., 1988) to the current sales research (Pettijohn, Pettijohn, \& Taylor, 2007).

The discourse of service-orientation in this study combines with the customer orientation known in the sales research. It describes the consumer's experiences of the salesperson's communication style towards the consumer during the sales process. The perspective is not combined with a strategy of the seller's firm. Instead, in the narratives of this study, the consumer's conclusions concerning the salesperson's communication style are often legitimized by specific arguments, such as "an excessively aggressive communication style would give a negative first impression," and "it is obvious that a good, professional, and customer service-oriented salesperson doesn't communicate in the way these salespersons did." All definitions of the discourse underline both verbal and nonverbal impressions, and attitudes that came true in the seller's behavior that strengthen or weaken the consumer's willingness to interact with the seller. Focusing on these characteristics, we claim that consumer-orientation as a speech code produces the discourse of service-orientation.

In the narrative of the active seller, the salesperson's active communication style is considered service-oriented and appropriate. The salesperson's active communication style is described as being bold and humorous. The narrative also shows how the salesperson's active communication style is legitimized by describing that if the salesperson's had a more aggressive communication style, it would have been inappropriate.

\begin{abstract}
We entered the store and started to walk around. The salesperson approached us during the first 30 seconds after we arrived in the store. She walked towards us and asked in the typical casual Savo style: "Hello, may I help you?" We gave the standard response that we were just looking. The salesperson answered: "No problem. What would you like to look at?" Her answer was rather bolder than we were used to, but it was very appropriate to the situation and amused us appropriately. Our first impression of the salesperson was that she was relaxed and pleasant. If she had been more aggressive, it would have made the first impression negative. However, the tone of her communication was appropriate.
\end{abstract}

The narrative also indicates how the salesperson's imposing use of language is criticized and described as an inappropriate communication style that lacks experience of consumer orientation. In the narrative below, such interaction by a salesperson led to the consumer being unwilling to make a purchase.

\footnotetext{
We have to admit that she pushed too hard to close the sale. Maybe she wanted to go home, or maybe she was tired since it was almost closing time. However, this gave the impression that this was a hard sales situation. I don't like it when the salesperson tries to push a sale through ... I therefore lost my willingness to make a purchase.
}

In the narrative of the cooperative seller, the discourse of service-orientation includes a description of a salesperson's sensitive verbal and nonverbal communication style can increase a consumer's willingness to purchase, as the following quotation demonstrates: 
Secondly, the seller asked us exactly what we wanted and especially for what kind of use we needed the equipment. He listened attentively to our requests without interrupting us, leaving us to finish talking. The seller tried to identify our needs and problems by asking and listening, and he engendered trust by answering our questions ... He left us to try on the boots after helping us to find the right size. He stayed close to us; giving some useful advice ... He did not pressure us. He did not force us at all, but in a polite way he gave us advice about which product was, in his opinion, the best for our needs ... This strengthened my decision to make a purchase.

The narrative of the cooperative seller shows how the salesperson listens attentively without interrupting the consumer, which is underlined as important behavior for B2B sellers in the sales literature (Sujan et al., 1988; Malshe, 2004). Accordingly, service-oriented sales communication style is outlined as being sensitively active, listening carefully, being available, and not imposing on the consumers (Pettijohn et al., 2007). Emphasizing listening has a link to Finnish speech culture. Earlier communication studies indicate that in the Finnish adult education context, it is considered appropriate to listen carefully when the speaker is speaking (Wilkins, 2009) and active listening is one of the key actions to show social support in Finnish men's friendships (Virtanen, 2015).

The following narrative of the withdrawing seller shows a case of the salesperson's inappropriate service-oriented communication style:

When I entered the store, I noticed one salesperson behind the cash desk and I slowly passed by the desk looking at the salesperson all the time. Purposely, I did not say anything. I waited to see if the salesperson would react to me. She didn't. Instead, she focused on doing something else ... Then I decided to open my mouth and asked where I could find a product that I was looking for. The salesperson guided me to the product, but that was it. She did not ask me anything. She only answered my questions briefly and a bit reluctantly, and then she immediately left me alone. I felt that I had disturbed her work by asking questions ... However, it is obvious that a good, professional, and customer service-oriented salesperson doesn't communicate the way the salesperson did. I don't have any reasons to go back to the seller.

In the previous quotation, the lack of consumer-orientation produces the dark side of the service-orientation discourse. The withdrawing seller does not demonstrate service-orientation at all, because she does not concentrate on selling, and therefore the consumer does not receive good customer service. It shows how the salesperson is not available, and when the consumer asks about the products, the salesperson guides the consumer to the products but she failed to proactively ask if she could be further assistance. She is not willing to serve the consumer. Therefore, the consumer feels that she is being left alone and that she is disturbing the seller's work. The consumer mentioned that she was not willing to continue the relationship with the company and she was not willing to buy the product.

\subsection{The discourse of professionalism}

In sales research, professionalism can be identified through the skills and knowledge required to be successful in selling (Marshall, Goebel, \& Moncrief, 2003). A list of success factors consists of items such as listening skills, follow-up skills, the ability to adapt one's selling style from situation to situation, persistence, verbal communication skills, proficiency in interacting with people at all levels within an organization, a demonstrated ability to overcome objections, closing skills, and personal planning and time management skills.

In this study, the discourse of professionalism describes consumers' experiences of professional and unprofessional salesperson-consumer interaction. Whereas the narratives of the active and collaborative seller outline a professional salesperson, the narratives of the withdrawing seller are built on unprofessionalism. Notions of unprofessional interaction are legitimized by specific arguments, such as "she did not use any sales tech- 
nique because she definitely didn't try to sell me anything." The discourse is based on consumers' experiences that came true in seller's talk and working methods (the different sales techniques they used). Focusing on these characteristics, we claim that fact-orientation as a speech code builds the discourse of professionalism.

In the following example of the narrative of the active seller, professionalism is valued in the description of the salesperson's successful completion of the sales process (except for pushing to close the sale), as well as her interpersonal communication skills.

We asked about the price. The salesperson started presenting a wide variety of sofas. She also presented two alternative sofas that were similar to the one we had asked about. Her communication style was relaxed and she had an open stance. Her hands were loosely beside her body. She did not try to be overbearing in her presentation. Instead, she was sensitive enough to listen to our questions and wishes, as a good salesperson should do. She answered us professionally... [However] We have to admit that she pushed too hard to close the sale.

As the previous quotation shows, professionalism includes delivering the sales presentation accordingly by providing two different alternatives and focusing on the consumers' interests (price), taking a relaxed and open position, focusing on facts in the sales talk, and giving professional answers. Fact-orientation may have its roots in Finnish speech culture, because focusing on facts has been found to be typical, at least in adult education contexts (Poutiainen \& Gerlander, 2009; Wilkins, 2005, 2009).

In the narrative of the cooperative seller, the discourse of professionalism is constructed by the notions of the salesperson's interpersonal communication skills, such as asking appropriate questions related to the consumer's needs (Jobber \& Lancaster, 2012, p. 253), listening attentively (Malshe, 2004), the salesperson's knowledge related to products, and the use of appropriate sales techniques (Evans et al., 2012). The professional salesperson is willing to focus on consumers' needs and solving consumers' problems (Moncrief \& Marshall, 2005). In addition, it is considered professional to focus on facts when talking about and describing products. Professionalism is further linked to service-orientation and also to the consumer's experience of building trust between the salesperson and the consumer.

He was a middle-aged man, and his appearance was professional and reliable. He greeted us cordially and asked us what exactly we were looking for. He ascertained if we wanted skating or traditional skis. His first sentences were short but complete, and talking in this way he presented himself to us as competent and an expert on skiing matters. Thus, the seller created a good feeling and increased our confidence by listening to us ... We can say that the seller solved our problem by showing us a product that met our needs very well ... We can argue that the seller's sales technique was good. The sales technique consisted of a professional product presentation, informal but technical advice, and attentive listening ... In general, his speech was quite professional.

In the narrative of the withdrawing seller, the discourse of professionalism focuses on unprofessional sales-related communication that lacks fact-oriented talk. The narratives show how the impression of unprofessionalism is constructed by a salesperson's reluctance to provide consumer service. The salesperson does not use sales techniques, does not try to sell the products, does not compare different products, and does not try to close the sale or sell anything extra; the consumer makes the purchasing decision by herself or himself. Unprofessionalism is also related to the consumer's way of using humor instead of direct criticism, which reduces the power of the argumentation.

She did not use any sales technique because she definitely didn't try to sell me anything. I made the purchasing decision totally by myself and I looked for and compared different products by myself. The salesperson didn't sell me anything extra. I bought a few pairs of 
socks, but it was my own decision ... The most ridiculous thing in this sales process was when I walked towards the cash desk and saw a sign hanging from the roof. It said: "Ask our expert salespeople for advice." Well, the salespersons might be experts, but if they don't want to share this expertise, the customer may never find it out. Maybe I should have been more aggressive and demanded this expertise.

\subsection{The discourse of independence} The discourse of independence is based on the consumer's freedom of choice concerning communication with the salesperson, the salesperson's availability in the store, and the consumer's purchasing decision. Sellers are expected to participate in the sales process by waiting in the wings until service is needed. In the sales research, allowing the customer independence is linked to the salesperson's ability to be flexible in adapting new selling styles and modifying her or his behavior when it is needed for successful interaction with the customer (Sujan et al., 1988).

In the narratives of the active and cooperative seller, the discourse of independence describes the consumer's positive freedom of choice and the salesperson's ability to be available when needed. In the narratives of the withdrawing seller, the discourse of independence describes how the consumer has too much freedom of choice and how the salesperson is not available, both of which are interpreted negatively. As a result, we therefore address independency as a speech code that builds the independence discourse in the study.

In the narrative of the active seller, the discourse of independence includes the salesperson's open and positive verbal and nonverbal communication as well as the willingness to be in contact with the consumers and serve them in a sensitive manner. The consumers, however, wish to be independent and they want to look at the products by themselves. The following example of the narrative shows that only when consumers are ready will they ask the salesperson's advice.
We said that we were just looking and we would ask for help if we needed it. We continued strolling around, and we a saw a sofa that we wanted to ask about. The salesperson had moved away from the counter and she had followed us and was coming to towards us.

Independence refers to the consumer's freedom of choice concerning communication with the salesperson, which is supported by the business literature on consumer decision-making processes (e.g., Blackwell et al., 2003). Independence might also have a connection to Finnish speech culture. In a study of Finnish advisor-advisee relationships, Poutiainen and Gerlander (2009, p. 109) suggested that independence could be approached as a cultural code.

In the narrative of the cooperative seller, the consumer's independence and equality are considered important elements of the sales communication. Independence is mostly linked to the consumer's freedom of choice concerning the purchasing decision, which the salesperson needs to respect. The salesperson also strengthens the consumer's freedom of choice by leaving them alone to think about the purchasing decision and by saying that he or she will be available when needed, as the following quotation shows:

\footnotetext{
We told him that we were not interested in other products, but only in the skis and maybe the boots and poles. So he did not insist on proposing any complementary products. He focused his efforts on the offer, which included a pair of skis, poles, and the related boots. He left us alone in order to let us think about the products saying that if we had any doubts or problems, he was always available.
}

In the following example of the narrative of the withdrawing seller, the discourse of independence is produced through inappropriately independent talk defining too wide amount of independency. The discourse describes how the consumer has too much freedom of choice and how the salesperson is not available during the sales process. The salesperson guides the consumer to the products but does not try 
to identify the consumer's further needs. Finally, the salesperson only answers the consumer's questions briefly, and the consumer is left alone to make the purchasing decision:

The salesperson guided me to the products, but that was it. She did not ask me anything, and she did not try to identify my needs. She only answered my questions briefly and then immediately left me alone ... I made the purchasing decision totally by myself and I looked for and compared different products by myself.

\section{Discussion}

The earlier business research emphasizes the buyers' decision-making (Blackwell et al., 2003; Jobber \& Lancaster, 2012) and the performance of salespeople (Moncrief and Marshall, 2005) as the main processes of sales. We expand the earlier research via three discourses that were produced in the interaction between salespeople and consumers in a B2C selling context in Finland. The results inform how Finnish speech culture is embedded in the sales-related discourses of service-orientation, professionalism, and independence.

The discourses have a strong influence on sales outcomes, meaning a consumer's willingness and unwillingness to be in contact with a salesperson, as provided particularly in the discourse of service-orientation among all the narratives. In these situations, appropriate salesperson-consumer interaction produced a positive experience for the consumer, which, in turn, has a positive effect on the consumer's purchasing decision and willingness to continue the interaction with the seller. Jokiniemi (2014) states that sales outcomes can be understood through an interaction-based value that increases from the ground of interpersonal interaction in a shared and relational context. Value appreciation specifically takes place at a personal level and is experienced as an outcome.

We found that each of the discourses were built through a speech code: Ser- vice-orientation was produced through the speech code of customer-orientation, professionalism was founded on the speech code of fact-orientation, and independence was based on the speech code of independency. The discourses therefore draw on the characteristics of the speech codes that prior research claims are typical of Finnish speech culture.

The discourse of service-orientation emphasizes the salesperson's willingness to be in contact with and to cooperate with the consumer, and the salesperson's attentive listening and sensitivity towards the consumer. Service-orientation in particular means that sellers need to have a lot of understanding in order to choose whether or not they take a moment in active, passive, or cooperative communication with both verbal and nonverbal communication. Such service-orientation is built through the speech code of consumer-orientation that strengthens the consumer's purchasing decision and willingness to interact with the seller, which can be understood as a successful sales outcome (Jokiniemi, 2014). Previous studies have shown that customer-oriented communication (Vadi \& Suuroja, 2006) and sales encounter satisfaction (Van Dolen, Lemmink, Ruyter, \& Jong, 2002) are related to more successful interaction between the customer and the salesperson. Moreover, the importance of salespersons' listening skills has also been highlighted in previous studies (Malshe, 2004). The results indicate that bold and humorous arguments can be considered appropriate in $\mathrm{B} 2 \mathrm{C}$ sales communication in Finland, which in turn questions the stereotype of Finns as silent communicators (Sallinen-Kuparinen, 1986; Wilkinson \& Isotalus, 2009).

In the discourse of professionalism, Finnish speech culture emerges through the focus on facts in the sales talk. Facts were also combined with talk that is well detailed (e.g., price), narrow (e.g., professional answers), true (supported through the verbal and nonverbal behavior of a seller), and logical (e.g., featuring argumentation). Focusing on the facts has been found to be typical of Finnish speech culture, especially in educational settings 
(Poutiainen \& Gerlander, 2009; Wilkins, $2005,2009)$. Therefore, we argue that the speech code of fact-orientation seems to be present in $\mathrm{B} 2 \mathrm{C}$ sales contexts in Finland as well. In the earlier business research, salespeople were highly expected to increase buyers' awareness, comprehension, and conviction towards their product offering during sales processes (Moncrief \& Marshall, 2005), as well as during purchasing processes (Blackwell et al., 2003). A seller's professionalism is also related to a seller's detailed knowledge on how to use targeting settings (Sujan et al., 1988) and facts as a part of a seller's argumentation in sales. In this study, we highlight the importance of this novel result: fact-oriented talk as a key element of the seller's professionalism that supports the consumer's trust in the seller and the consumer's willingness to interact with the salesperson. It can be therefore understood as a successful sales outcome. Future studies should explore whether fact-orientation is a speech code that is present in salesperson-consumer interaction in the $\mathrm{B} 2 \mathrm{C}$ context not just in Finland but also outside of Finland in this context.

The discourse of independence involves the consumer's freedom of choice in communicating with the salesperson and in his or her decision-making (Malshe, 2004). The discourse in particular highlights the requirement for consumers' autonomy, which is quite a common expectation among individuals in Western cultures. Likewise, independence could have a connection to Finnish speech culture. In a study of Finnish advisor-advisee relationships, Poutiainen and Gerlander (2009, p. 109) suggested that independence could be approached as a cultural code. We suggest that independence could be approached as a speech code that is present in salesperson-consumer interaction in the $\mathrm{B} 2 \mathrm{C}$ context.

In light of our results, we suggest that consumer-orientation could be approached as a speech code that is present in salesperson-consumer interaction in the B2C context. Speech codes theory states that people use speech codes not only to interpret communicative conduct but also to evaluate it, explain it, and justify it (Philipsen, 2008). We suggest that the three discourses found in this study formulate a cultural norm that can be suggested as being relevant in B2C sales contexts. According to Carbaugh (2007, p. 178), communication norms are statements about conduct that are granted some degree of legitimacy by the participants in a speech event or a speech community. Norms may be stated by the participants themselves, but they can also be implicit in the structuring of discourse (Carbaugh, 2007, p. 178). We argue that appropriate salesperson-consumer interaction in Finland is based on the salesperson's service-orientation built by consumer-orientation (willingness to be in contact with and to cooperate with the consumer, attentive listening, sensitivity), professionalism (and particularly fact-oriented talk),

Figure 2: The influence of appropriate or inappropriate salesperson-consumer interaction HERE

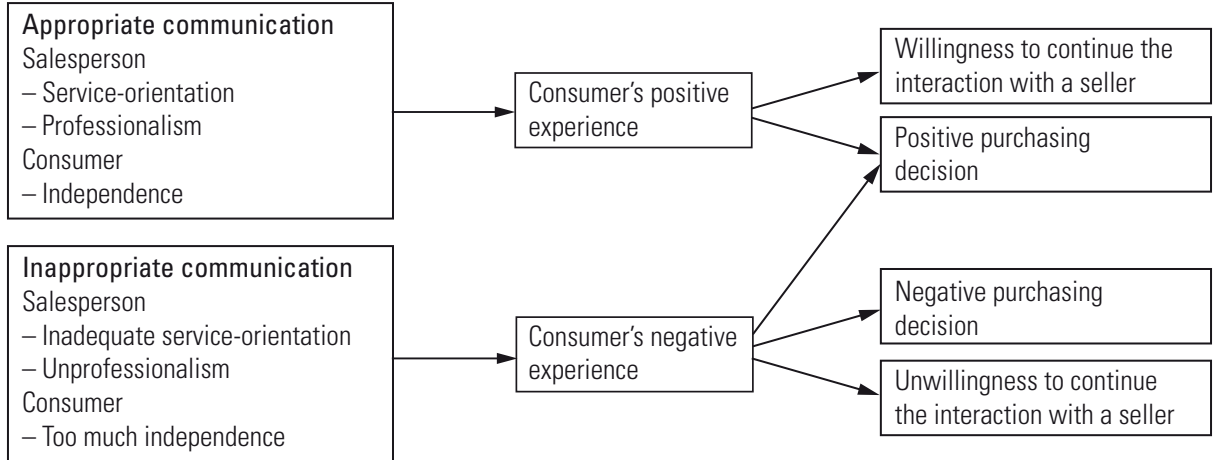


and the consumer's independence. Appropriate salesperson-consumer interaction also produces a positive experience for the consumer, which, in turn, has a positive effect on the consumer's purchasing decision and willingness to continue to interact with the seller in the future.

Our study shows that inappropriate salesperson-consumer interaction is based on the salesperson's lack of professionalism, inadequate consumer-orientation, and assigning too much independence to the consumer. Thereafter, inappropriate salesperson-consumer interaction produces a negative experience for the consumer. This negative experience may or may not affect the consumer's purchasing decision and the consumer's willingness to continue to interact with the seller in the future. The influence of appropriate or inappropriate salesperson-consumer interaction on the consumer's experience and purchasing behavior is depicted in Figure 2.

\section{Conclusion}

The results of the study point out that the discourses of service-orientation, professionalism, and independence are strongly valued in the discourse of the narratives in this study. The salesperson's consumer-orientation, fact-oriented talk (as a central element of a salesperson's professionalism), and the consumer's independency can be seen as speech codes in the B2C sales context in Finland. The cultural knowledge circulated in the narratives describes how salesperson-consumer interaction, which is considered successful in the Finnish context, is based on the appropriateness of the sales interaction between consumers and sellers. Appropriateness is produced via positive experiences for the consumer, which positively affects the consumer's purchasing decisions and willingness to continue to interact in the future. On the other hand, inappropriate salesperson-consumer interaction produces a negative experience for the consumer that may or may not affect the consumer's purchasing decision. However, the consumer's negative experience leads to unwillingness to continue to interact in the future.

Van Dolen and his colleagues (2002) have suggested that it is important for firms to focus on both the management of customer perceptions and on the management of the salesperson's perceptions of their own performance. Sujan and his co-authors (1988) encourage salespeople to be analytical about their skills, outcomes, and failures in sales. Openness is needed to see mistakes and develop skills. This study confirms this idea and suggests sales managers should focus on training how salespersons' interaction with their consumers can produce better customer experiences. The training should focus on strengthening salespeople's professionalism (including the content of fact-oriented talk), interpersonal communication skills (including understanding the customer's willingness to be in interaction with the salesperson), and informing them about speech codes (e.g., aiming for fact-oriented talk in the B2C context and respecting the consumer's independence are useful areas for salespeople to focus on). In this study, speech codes were shown to be part of the consumer's decision-making during the purchasing process. Therefore, they might influence the development of firms' competitive advantage as well.

Even though the speech codes found in our study seem to have a connection to Finnish speech culture, these speech codes might also come to life in $\mathrm{B} 2 \mathrm{C}$ selling contexts in other cultural environments as well. This study concentrated on the consumer's point of view, based on their experiences related to salesperson-customer interaction. In future research, it could be very fruitful to add the seller's opinion to the exploration. Moreover, the results of our qualitative study could be further tested. It would be interesting to continue exploring salesperson-consumer interaction in actual sales situations in other countries besides Finland. By understanding the speech codes embedded in different national cultures, managers can guide their salespeople to communicate more appro- 
priately in order to build long-lasting relationships with profitable consumers.

\section{References}

Abratt, R. \& Kelly, P. M. (2002). Customer-supplier partnerships: perceptions of a successful key account management program. Industrial Marketing Management, 3, 467-476.

Berry, M., Carbaugh, D., \& Nurmikari-Berry, M. (2004). Communicating Finnish quietude: a pedagogical process for discovering implicit cultural meanings in languages. Language and Intercultural Communication, 4, 261-280.

Blackwell, R. D., Miniard, P. W., \& Engel, J. F. (2003), Consumer Behaviour. Orlando: Dryden.

Bruner, J. (1986). Actual Minds, Possible Words. Cambridge, MA: Harvard University Press.

Carbaugh, D. (1995). Are Americans really superficial? Notes on Finnish and American cultures in linguistic action. In L. L. Salo (Ed.), Kieli ja kulttuuri oppimisessa ja opettamisessa [Language \& culture in learning and teaching] (pp. 53-60). Jyväskylä, Finland: University of Jyväskylä.

Carbaugh, D. (2007). Cultural discourse analysis: Communication practices and intercultural encounters. Journal of Intercultural Communication Research, 36, 167-182.

Carbaugh, D. (2009). Coding personhood through cultural terms and practices: Silence and quietude as a Finnish natural way of being. In R. Wilkins \& P. Isotalus (Eds.), Speech Culture in Finland (pp. 4362). Lanham, MD: University Press of America.

Calder, B. J. \& Tybout, A. M. (1987). What Consumer Research Is. Journal of Consumer Research, 136-140.

Czarniawska, B. (1999). Interviews, Narratives and Organizations. Gothenburg, Sweden: Gothenburg Research Institute.

Decormier, R. and Jobber, D. (1993). The counsellor selling method: concepts, constructs and effectiveness. Journal of Personal Selling and Sales Management, 13(4), 39-60.

Edwards, D. (1997). Discourse and Cognition. Sage: London.
Evans, K. R., McFarland, R. G., Dietz, B., \& Jaramillo, F. (2012). Advancing sales performance research: A focus on five under researched topic areas. Journal of Personal Selling \& Sales Management, 32(1), 89-105.

Focault, M. (1982). The archaeology of knowledge and the discourse on language. New York, NY: Pantheon Books.

Friestad, M. \& Wright, P. (1994). The persuasion knowledge model: How people cope with persuasion attempts. Journal of Consumer Research, 1-31.

Gilliam, D. A. \& Flaherty, K. E. (2015). Storytelling by the sales force and its effect on buyer-seller exchange. Industrial Marketing Management, 46,132-142.

Graham, R. (1997). Commercial negotiations. In Jobber, D. (Ed.) The CIM Handbook of Selling and Sales Strategy (pp. 34-52). Oxford: Butterworth-Heinemann.

Guenzi, P. \& Storbacka, K. (2015). The organizational implications of implementing Key Account Management: A case-based examination. Industrial Marketing Management, 45 (February), 84-97.

Hall, C. (1997). Social work as narrative storytelling and persuasion in professional texts. Aldershot: Ashgate.

Haytko, D. L. (2004). Firm-to-Firm and Interpersonal Relationships: Perspectives from Advertising Agency Account Managers. Journal of the Academy of Marketing Science, 32, 312-328.

Hung, K-P. \& Lin, C-K. (2013). More communication is not always better? The interplay between effective communication and interpersonal conflict in influencing satisfaction. Industrial Marketing Management, 42(8), 1223-1232.

Isotalus, P. (2009). Agreement and disagreement in focus: a cultural perspective on televised election debates. In R. Wilkins \& P. Isotalus (Eds.), Speech Culture in Finland (pp. 191-208). Lanham, MD: University Press of America.

Jobber, D. \& Lancaster, G. (2012). Selling and Sales Management. Harlow: Pearson Education Limited.

Jokiniemi, S. (2014). “Once again I gained so much"- Understanding the value of business-to-business sales interactions from an individual viewpoint. Turku, Finland: University of Turku. 
Kirmani, A. \& Campbell, M. C. (2004). Goal Seeker and Persuasion Sentry: How Consumer Targets Respond to Interpersonal Marketing Persuasion. Journal of Consumer Research, 31 (December), 573-583.

Lek, M., Karczewski, K., Minikel, E., Samocha, K., Banks, E., Fennell, T., ..., \& Tukiainen, T. (2016). Analysis of protein-coding genetic variation in 60,706 humans. BioRxiv, 030338.

Makkonen, H., Aarikka-Stenroos, L., \& Olkkonen, R. (2012). Narrative approach in business network process research - Implications for theory and methodology. Industrial Marketing Management, 41, 287-299.

Malshe, A. (2004). Relational listening and impression management in salesperson-customer relationships. Advances in Consumer Research, 31, 477-478.

Mason, K. \& Leek, S. (2012). Communication practices in a business relationship: Creating, relating and adapting communication artifacts through time. Industrial Marketing Management, 41(2), 319-332.

Miller, K. (2002). Communication Theories. Perspectives, Processes and Contexts. Boston, MA: McGraw Hill.

Miller, D. (Ed.) (1995). Acknowledging Consumption: A Review of New Studies. London: Routledge.

Moncrief, W. C. \& Marshall, G. W. (2005). The evolution of the seven steps of selling. Industrial Marketing Management, 34(1), 13-22.

Marshall, G. W., Goebel, D. J. \& Moncrief, W. C. (2003). Hiring for success at the buyer-seller interface. Journal of Business Research, $56,247-55$.

Pecoraro, M. G. \& Uusitalo, O. (2014). Conflicting values of ethical consumption in diverse worlds - A cultural approach. Journal of Consumer Culture, 14(1), 45-65.

Pettijohn, C. E., Pettijohn, L. S., \& Taylor, A. J. (2007). Does salesperson perception of the importance of sales skills improve sales performance, customer orientation, job satisfaction, and organizational commitment, and reduce turnover? Journal of Personal Selling \& Sales Management 27(1), 75-88.
Philipsen, G. (1992). Speaking Culturally: Explorations in Social Communication. Albany, NY: State University of New York Press.

Philipsen, G. (1997). A theory of speech codes. In G. Philipsen \& T. L. Albrecht (Eds.), Developing Communication Theories (pp. 119-156). Albany, NY: State University of New York Press.

Philipsen, G. (2008). Speech codes theory: Traces of culture in interpersonal communication. In L. A. Baxter \& D. O. Braithwaite (Eds.), Engaging Theories in Interpersonal Communication: Multiple Perspectives (pp. 269-279). Los Angeles, CA: Sage.

Philipsen, G. \& Carbaugh, D. (1986). A bibliography of fieldwork in the ethnography of communication. Language in Society, 15, 387-398.

Philipsen, G., Coutu, L. M., \& Covarrubias, P. (2005). Speech codes theory: Restatement, revisions, and response to criticisms. In W. Gudykust (Ed.), Theorizing About Intercultural Communication (pp. 55-68). Thousand Oaks, CA: Sage.

Phillips, N. \& Hardy, C. (2002). Discourse analysis: Investigating processes of social construction. Thousand Oaks, CA: Sage Publications.

Planken, B. (2005). Managing rapport in lingua franca sales negotiations: A comparison of professional and aspiring negotiators. English for Specific Purposes, 24, 381-400.

Polkinghorne, D.E. (1988). Narrative Knowing and the Human Sciences. Albany, NY: State University of New York Press.

Polkinghorne, D. E. (1995). Narrative configuration in qualitative analysis. International Journal of Qualitative Studies in Education, 8(1), 5-23.

Poutiainen, S. \& Gerlander, M. (2009). Cultural dialectics in Finnish advising relationships. In R. Wilkins \& P. Isotalus (Eds.), Speech Culture in Finland (pp. 85-116). Lanham, MD: University Press of America.

Rappaport, J. (2000). Community narrative: Tales of terror and joy. American Journal of Community Psychology,28(1), 1-24.

Sallinen-Kuparinen, A. (1986). Finnish communication reticence: Perceptions and self-reported behavior, 19. Jyväskylä, Finland: University of Jyväskylä.

Saxe, R. \& Weitz, B. (1982). The SOCO Scale: A Measure of the Customer-Orientation 
of Salespeople. Journal of Marketing Research, 19 (August), 343-351.

Sujan, H., Weitz, B. A., \& Sujan, M. (1988). Increasing sales productivity by getting salespeople to work smarter. Journal of Personal Selling \& Sales Management, 8(2), 9-19.

Thompson, C. (1997). Interpreting consumers: A hermeneutical framework for deriving marketing insights from the texts of consumers' consumption stories. Journal of Marketing Research, 34 (November), 438-455.

Thompson, C. J. (2004). Marketplace mythology and discourses of power. Journal of Consumer Research, 31(1), 162-80.

Thompson, C. J. \& Haytko, D. L. (1997). Speaking of fashion: Consumers' uses of fashion discourses and the appropriation of countervailing cultural meanings. Journal of Consumer Research, 24(1), 15-42.

Thompson, C. J. \& Hirschman, E. C. (1995). Understanding the socialized body: A poststructuralist analysis of consumers' self-conceptions. Journal of Consumer Research, 22(2), 139-53.

Vaahterikko-Mejía, P. (2009). The meaning of intangibles in international business relations: Latin American perceptions of Finns as negotiators. In R. Wilkins \& P. Isotalus (Eds.), Speech Culture in Finland (pp. 115-70). Lanham, MD: University Press of America.

Vadi, M. \& Suuroja, M. (2006). Training retail sales personnel in transition economies: Applying a model of customer-oriented communication. Journal of Retailing and Consumer Services, 13(5), 339-49.

Van Dolen, W., Lemmink, J., Ruyter, K., \& Jong, A. (2002). Customer-sales employee encounters: a dyadic perspective. Journal of Retailing. 78, 265-279.

Van Laer, T., Ruyter, K., Visconti, L. M., \& Wetzels, M. (2014). The extended transportation imagery model: A meta-analysis of the antecedents and consequences of consumers' narrative transportation. Journal of Consumer Research, 40(5), 797-817.

Virtanen, I. A. (2015). Supportive Communication in Finnish Men's Friendships, Academic dissertation, Acta Universitatis Tamperensis 2019, Tampere, Finland.
Välikoski, T-R. (2009). The Finnish criminal trial as a speech communication situation. In R. Wilkins \& P. Isotalus (Eds.), Speech Culture in Finland (pp. 171-190). Lanham, MD: University Press of America.

Warde, A. (2005). Consumption in theories of practice. Journal of Consumer Culture, 5(2), 131-153.

Weitz, B. A. (1981). Effectiveness in sales interactions: a contingency framework. Journal of Marketing, 45, 85-103.

Weitz, B. A., Sujan, H., \& Sujan, M. (1986). Knowledge, motivation, and adaptive behavior: A framework for improving selling effectiveness. The Journal of marketing, 174-191.

Whyte, W. F. (1984). Learning from the Field: A Guide from Experience. Beverly Hills, CA: Sage.

Wilkins, R. (2005). The optimal form: inadequacies and excessiveness within the asiallinen [matter of fact] nonverbal style in public and civic settings in Finland. Journal of Communication, 55, (2), 383-401.

Wilkins, R. (2009). The asiasta puhuminen event. In R. Wilkins \& P. Isotalus (Eds.), Speech Culture in Finland (pp. 63-84). Lanham, MD: University Press of America.

Wilkins, R. \& Isotalus, P. (2009) Finnish speech culture. In R. Wilkins \& P. Isotalus (Eds.), Speech Culture in Finland (pp. 1-16). Lanham, MD: University Press of America.

Williams. A. J. \& Seminerio, J. (1985). What buyers like from salesmen. Industrial Marketing Management, 14(2), 75-78. 